\title{
Early versus late lateral ventricular enlargement following closed head injury
}

\author{
CA MEYERS, HS LEVIN, HM EISENBERG, FC GUINTO \\ From the Divisions of Neurosurgery and Neuroradiology, University of Texas Medical Branch, Galveston, \\ Texas, USA
}

SUMMARY Serial computed tomographic scans in 39 closed head injury patients were measured by planimetry. The ventricle-brain ratio was computed, and the lateral ventricles were considered to be enlarged or normal based on measurements from a control group. Delayed ventricular enlargement was common after head injury producing low Glasgow Coma Scale scores and prolonged coma, whereas subarachnoid/intraventricular haemorrhage was more common with early enlargement. The degree of ventriculomegaly was related to neuropsychological test performance only when enlargement was delayed. It is postulated that diffuse axonal injury and hypoxic-ischaemic insult contributed to late ventricular enlargement, whereas a compensated obstruction of cerebrospinal fluid may be the predominant cause in the early group.

Strich $^{12}$ found that ventriculomegaly was a frequent antemortem finding in patients who survived following head injury for periods varying from two months to two years in a profoundly demented condition. Although she inferred that the ventricular enlargement was a consequence of the space left by degeneration of the white matter which was conspicuous around the lateral ventricles, other mechanisms including hypoxic-ischaemic insult were undoubtedly contributory. ${ }^{3}$ Our previous investigation of ventricular enlargement in young adults who survived a severe closed head injury disclosed that $72 \%$ of the patients had lateral ventricles which had enlarged beyond the range of an age-matched control group. ${ }^{4}$ Ventricular enlargement was generally associated with longer coma duration and intellectual and memory deficits. However, we also noted some striking discrepancies, namely enlarged ventricles despite brief coma and satisfactory neuropsychological recovery, particularly in patients who exhibited ventricular enlargement early in their course of recovery.

In view of our previous findings, we postulated that delayed ventricular enlargement following head injury would be related to the severity of acute

Address for reprint requests: Harvey S Levin, $\mathrm{PhD}$, Division of Neurosurgery, University of Texas Medical Branch, Galveston, Texas 77550, USA

Received 2 November 1982 and in revised form 28 April 1983 Accepted 20 June 1983 impairment of consciousness as reflected by the initial Glasgow Coma Scale ${ }^{5}$ score and the duration of coma. In contrast, we predicted that this relationship would be weaker in patients with early ventricular enlargement in whom hydrocephalus is the presumptive mechanism. We postulated that late (but not early) ventricular enlargement reflects severe diffuse btain injury due to both axonal injury and hypoxicischaemic insult (but does not exclude the presence of a focal lesion). Consequently, we hypothesised that neuropsychological recovery would be negatively related to ventricular size in late enlargers but unrelated to ventricular size in early enlargers if their ventricular dilatation were due, at least in part, to compensated hydrocephalus.

\section{Methods}

\section{Subjects}

The subjects were a consecutive series of 39 patients with closed head injury who had serial CT scans and were under 50 years old at the time of injury. No patient had a prior history of neurological disorder, psychiatric illness or alcoholism. Participation was limited further to patients who had serial CT scans performed at intervals after injury which allowed us to estimate the temporal course of changes in ventricular size. Table 1 displays the demographic and clinical characteristics of the total series. The severity of injury was evaluated by the duration of coma, which is a widely accepted index of diffuse injury ${ }^{6}$ and by the Glasgow Coma Scale ${ }^{5}$ score obtained on admission. Severe injuries are defined on the Glasgow Coma Scale as a total score of 8 or less (ceiling score is 15), that is, no eye opening, inability to follow commands, and failure to utter comprehensible words. We defined the end of coma as the point in time 
Table 1 Demographic and clinical characteristics of patients with closed head injuries

\begin{tabular}{|c|c|c|c|c|c|}
\hline & $\begin{array}{l}\text { Total } \\
\text { series } \\
(n=39)\end{array}$ & $\begin{array}{l}\text { Early } \\
\text { enlargers } \\
(n=16)\end{array}$ & $\begin{array}{l}\text { Undated } \\
\text { enlargers } \\
(n=6)\end{array}$ & $\begin{array}{l}\text { Late } \\
\text { enlargers } \\
(n=8)\end{array}$ & $\begin{array}{l}\text { Patients with } \\
\text { normal VBRs } \\
(n=9)\end{array}$ \\
\hline \multicolumn{6}{|l|}{ Age (yr) } \\
\hline Median & $19 \cdot 8$ & $23 \cdot 5$ & $18 \cdot 5$ & $19 \cdot 5$ & $18 \cdot 3$ \\
\hline Range & $5-41$ & $5-41$ & $8-25$ & $16-28$ & $13-37$ \\
\hline \multicolumn{6}{|l|}{ Coma duration (days) } \\
\hline Median & $4 \cdot 0$ & $3 \cdot 5$ & $12 \cdot 25$ & $11 \cdot 5$ & $1 \cdot 0$ \\
\hline \multirow{2}{*}{\multicolumn{6}{|c|}{ Initial Glasgow Coma Scale Score }} \\
\hline & & & & & \\
\hline Median & $7 \cdot 0$ & $7 \cdot 0$ & $6 \cdot 0$ & $4 \cdot 0$ & $8 \cdot 0$ \\
\hline Range & $3-15$ & $3-14$ & $3-9$ & $3-8$ & 4-15 \\
\hline$\% \leqslant 8$ & 77 & 75 & 83 & 100 & 55 \\
\hline \multicolumn{6}{|l|}{ Type of injury $(n)^{*}$} \\
\hline Intraventricular haemorrhage/SAH & 4 & 3 & 1 & 0 & 0 \\
\hline Intracerebral haematoma/contusion & 11 & 4 & 2 & 1 & 4 \\
\hline Extracerebral haematoma/contusion & 15 & 8 & 2 & 5 & 0 \\
\hline Diffuse & 11 & 3 & 1 & 2 & 5 \\
\hline \multicolumn{6}{|l|}{$\begin{array}{l}\text { Interval between injury and first appearance of } \\
\text { ventricular enlargement (days) or last normal VBR }\end{array}$} \\
\hline Median & $28 \cdot 1$ & $18 \cdot 5$ & & 230 & $440 \ddagger$ \\
\hline & $9-1182$ & $0-28$ & $40-331$ & $72-1182$ & $51-1145$ \\
\hline \multirow{2}{*}{\multicolumn{6}{|c|}{$\begin{array}{l}\text { Interval between injury and neuropsychological } \\
\text { test (months) } \dagger\end{array}$}} \\
\hline & & & & & \\
\hline $\begin{array}{l}\text { Median } \\
\text { Range }\end{array}$ & $\begin{array}{l}11 \cdot 8 \\
(1-60)\end{array}$ & $\begin{array}{l}9 \cdot 8 \\
1-38\end{array}$ & $\begin{array}{l}12 \\
2-28\end{array}$ & $\begin{array}{l}0 \cdot 3 \\
5-45\end{array}$ & $\begin{array}{r}12 \cdot 1 \\
2-39\end{array}$ \\
\hline
\end{tabular}

${ }^{*}$ Based on results of CT scan within one week of injury.

$\dagger$ The minimum follow-up interval was six months in patients who initially exhibited a deficit. The baseline data were used in the few cases with normal findings on the initial neuropsychological assessment.

$\ddagger$ VBR obtained from the latest (and earlier) CT scan was normal.

when the patient first followed commands, exhibited eye opening, and uttered comprehensible words (unless they were intubated). The Glasgow Coma Scale scores and coma durations are summarised in Table 1.

\section{Procedures}

The CT slice showing the greatest apparent lateral ventricular area was used to measure the intracranial and ventricular areas by planimety from which the ventricle brain ratio (VBR) was computed. The VBR ((ventricular area/ intracranial area) $\times 100$ ) was then computed for each scan. ${ }^{7}$ The VBRs were classified as normal or enlarged based upon a control group of 51 individuals who had been referred for scanning because of headache, psychiatric complaints, or pain, without demonstrable neurologic deficit. All control subjects were under 40 years of age (median $=29$, range = 18-39) and had no abnormalities on the CT scan according to a neuroradiologist (FCG), and no history of substance abuse or chronic schizophrenia. The neuroradiologist also rank ordered the CT scans of the closed head injury patients according to the width of the cortical sulci. ${ }^{8}$ The CT scan of each patient which demonstrated the largest VBR was used for rank ordering the width of the sulci.

Neuropsychological tests were administered contiguous in time to the CT scan in all but five closed head injury patients who had scheduling problems or were unable to cooperate. The cognitive tests included the Wechsler Adult Intelligence Scale (WAIS), the selective reminding verbal memory technique ${ }^{9}$ and the Paced Auditory Serial Addition Test (PASAT) which measures information processing rate. ${ }^{10}$ The Brief Psychiatric Rating Scale (BPRS) ${ }^{11}$ was used to assess behavioural disturbance. We employed the Thinking Disturbance and Total Psychopathology scores of the BPRS. These procedures have been shown to be sensitive measures of neurobehavioural outcome after severe closed head injury. ${ }^{12-14}$

\section{Results}

TEMPORAL COURSE OF VENTRICULAR ENLARGEMENT

The lateral ventricles of closed head injury patients were considered enlarged if they exceeded the largest control VBR (VBR > 7.7). According to this criterion, 30 closed head injury patients (77\%) developed ventricular enlargement during the course of the study.

Five "early enlargers" developed ventriculomegaly within one day after injury, including three cases with acute subarachnoid or intraventricular haemorrhage. One of these patients underwent an emergency ventriculostomy drainage and insertion of a ventriculoperitoneal shunt because of increased intracranial pressure and obtundation two days after a boxing injury which produced only a brief loss of consciousness. His initial CT findings were consistent with intraventricular and subarachnoid haemorrhage. Multiple scans over the next three months demonstrated progressive enlargement (the last CT yielded a VBR of 29.5). An additional case of very early ventricular enlargement had meningitis and one early enlarger had a subdural hygroma. Eleven closed head injury patients had small to normal ventricles (VBR between 0.1 and 7.7) for two weeks -after injury, but showed enlargement prior to 30 days 


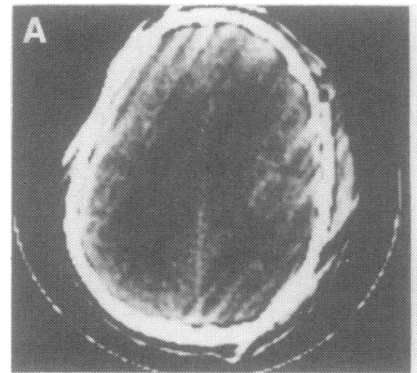

Day of injury
$\operatorname{VBR}=0.8$

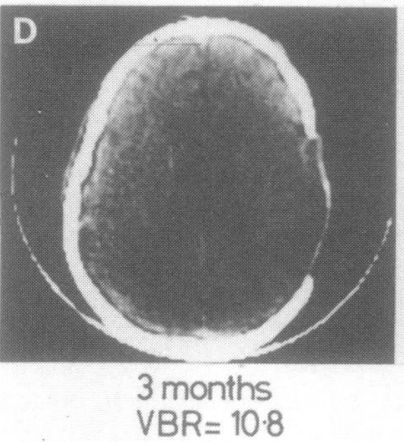

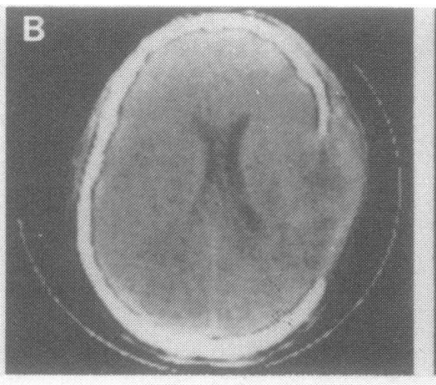

2 weeks

$\mathrm{VBR}=3 \cdot 0$

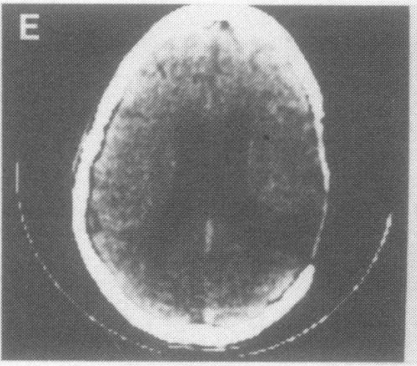

5 months

$\operatorname{VBR}=12 \cdot 3$
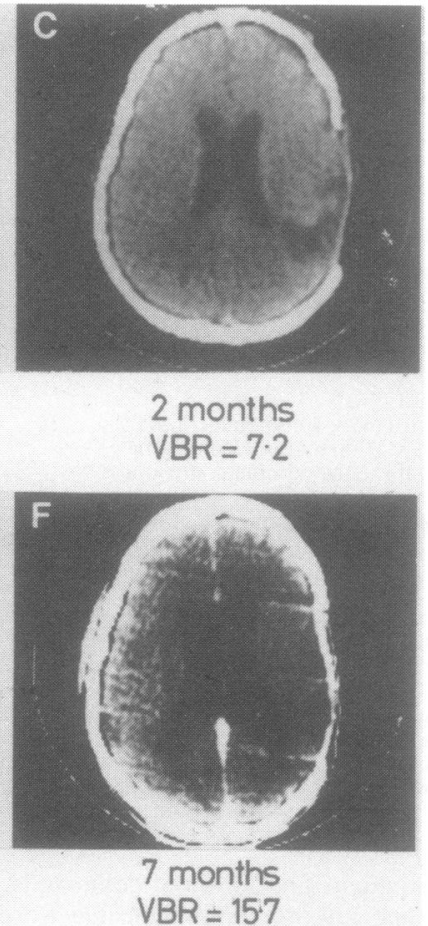

Fig 1 Progressive lateral ventricular enlargement after 1 month in a patient who was admitted with a Glasgow Coma Scale score of 4 and remained unresponsive to simple commands for six months.

after injury. A total of 16 patients, including the five very early enlargers, were considered "early enlargers" (median VBR $=11.8$, range $=8 \cdot 8-29 \cdot 5$ ), according to this one month limit.

"Late enlargers" maintained normal ventricular size for 30 days after injury and subsequently showed enlargement (median VBR $=12 \cdot 1$, range $=7 \cdot 8$ 20.7). Figure 1 shows the serial CT scans of a patient who developed late ventricular enlargement. Another group of "enlargers" $(n=6)$ consisted of individuals who had normal scans at least 14 days after injury and later showed enlargement (median VBR $=9 \cdot 7$, range $=8 \cdot 2-19 \cdot 2)$. Their data were analysed separately (Undated Group in tables 1 and 2) since they did not have scans between 14 and 30 days, that is, their time course of ventricular enlargement is not as well documented. Nine closed head injury patients maintained normal ventricular size (median VBR $=4 \cdot 6$, range $=2 \cdot 6-6 \cdot 4$ ) after 30 days. No patient with late ventricular enlargement or normal VBRs had CT evidence of intraventricular or subarachnoid haemorrhage (table 1).

Fifteen of the "early enlargers" subsequently underwent one or more additional CT scans at least one month after injury. With a single exception whose VBR decreased minimally (from 9.8 to 9.4 ), the follow-up CT scan disclosed further ventriculomegaly in the early enlargers. In accord with this pattern, the five closed head injury patients (other than the "early enlargers") who had serial scanning after the first appearance of ventricular enlargement also showed further ventriculomegaly. With the exception of the very "early enlarger" who was shunted, these patients had no symptoms of progressive hydrocephalus.

\section{VENTRICULAR ENLARGEMENT IN RELATION} TO IMPAIRMENT OF CONSCIOUSNESS AND

SULCAL PROMINENCE

Table 1 shows a trend for lower Glasgow Coma Scale scores and a longer duration of impaired consciousness in patients who developed ventricular enlargement after one month after injury as compared to the early enlargers and patients with normal VBRs. "Late enlargers" ( $n=8)$ had a significantly lower Glasgow Coma Scale score on admission $(U=29.5$, $\mathrm{p}<0.03$ ) and a longer duration of coma (MannWhitney $U=32, p<0.05$ ) than the patients with early ventricular enlargement. The VBRs of individual patients are plotted against the duration of coma 


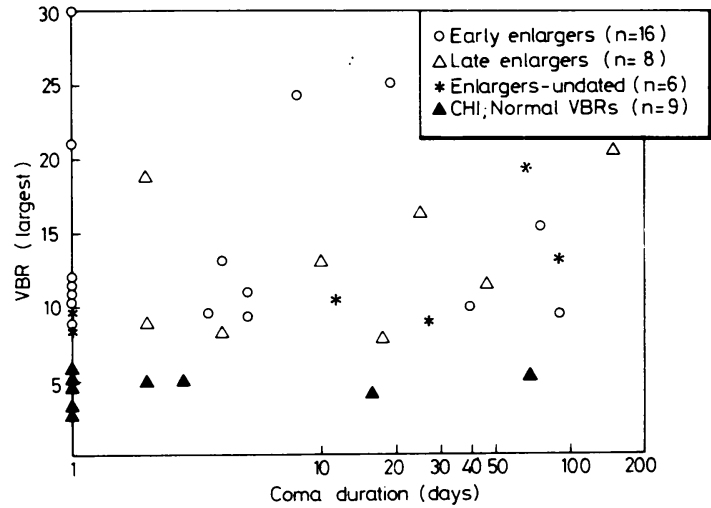

Fig 2 Individual ventricle brain ratios (VBRs) plotted against the duration of coma for the three groups of patients defined by the presence and temporal course of lateral ventricular enlargement. A significant correlation was obtained only for the patients who exhibited delayed ventricular enlargement.

in fig 2. It can be seen that the magnitude of the VBRs did not differ between the early and late enlargement groups. As depicted in fig 2, the degree of ventricular enlargement was strongly related to the duration of coma in closed head injury patients other than the early enlargers (Spearman rank order correlation coefficient $=0.59, \mathrm{p}<0.003)$ but this relationship was not found in patients with enlargement before 30 days $(r=-0 \cdot 15)$.

Analysis of the rank order of sulcal enlargement assigned by the neuroradiologist disclosed a significant relationship with the VBR for the total series $(r=0.54, p<0.002)$, that is, the patients who had the largest VBRs were also judged to have the most prominent sulci. In comparison with closed head injury patients who maintained normal ventricular size, the sulcal widths were judged to be wider in both the groups with early and late ventricular enlargement, respectively $(U=13, p<$ $0.02 ; \mathrm{U}=4, \mathrm{p}<0.03)$. Patients who developed ventricular enlargement within one month, however, did not differ in sulcal width from cases with late ventricular enlargement.

\section{NEUROPSYCHOLOGICAL RECOVERY}

Table 2 summarises the neuropsychological test results for these groups. Impairment on a test was defined as a score which fell more than two standard deviations below the mean of normal subjects. Neuropsychological test performance did not differ between the early and late groups on any measure. Irrespective of the temporal course of ventricular

Table 2 Neuropsychological test performance in relation to ventricular enlargement*

\begin{tabular}{|c|c|c|c|c|c|}
\hline Test & $\begin{array}{l}\text { Total } \\
\text { series }\end{array}$ & $\begin{array}{l}\text { Early } \\
\text { enlargers }\end{array}$ & $\begin{array}{l}\text { Undated } \\
\text { enlargers }\end{array}$ & $\begin{array}{l}\text { Late } \\
\text { enlargers }\end{array}$ & Normal VBR \\
\hline \multicolumn{6}{|c|}{ WAIS Full Scale IQ } \\
\hline n & 29 & 8 & 6 & 6 & 9 \\
\hline Median & & & $73 \cdot 5$ & $86 \cdot 5$ & 95 \\
\hline Range & $46-130$ & $51-130$ & $46-124$ & $70-108$ & $86-121$ \\
\hline$\%$ impaired & & & & & \\
\hline \multicolumn{6}{|c|}{$\begin{array}{l}\text { Selective Reminding } \\
\text { Total Long-Term Retrieval } †\end{array}$} \\
\hline n & 25 & 6 & 5 & 5 & 9 \\
\hline Median & & 98 & 107 & 49 & 76 \\
\hline Range & $5-131$ & $9-131$ & $5-121$ & $20-122$ & $18-126$ \\
\hline$\%$ impaired & 52 & & & & \\
\hline \multicolumn{6}{|c|}{ BPRS } \\
\hline \multicolumn{6}{|c|}{ Thinking Disturbance $\ddagger$} \\
\hline $\mathrm{n}$ & 33 & 13 & 5 & 7 & 8 \\
\hline Median & $3 \cdot 4$ & 3.8 & $4 \cdot 4$ & 3.4 & $3 \cdot 3$ \\
\hline Range & $3-13$ & $3-13$ & $3-7$ & $3-9$ & $3-9$ \\
\hline \% impaired & 36 & 38 & 40 & 43 & 38 \\
\hline \multicolumn{6}{|l|}{$\begin{array}{l}\text { PASAT } \\
\text { Trial } 1\end{array}$} \\
\hline n & 17 & 5 & 3 & 3 & 6 \\
\hline Median & 32 & 35 & 33 & 28 & 29 \\
\hline Range & $1-48$ & $1-46$ & $13-44$ & $15-32$ & $22-48$ \\
\hline \multirow{2}{*}{\multicolumn{6}{|c|}{ Trial 2}} \\
\hline & & & & & \\
\hline $\mathrm{n}$ & 15 & 5 & 3 & 3 & 5 \\
\hline Median & 28 & 31 & 26 & 8 & 25 \\
\hline Range & $5-46$ & $23-46$ & $12-44$ & $5-31$ & $14-46$ \\
\hline$\%$ impaired & 60 & & 33 & 67 & 60 \\
\hline
\end{tabular}

*There were no significant differences between these groups on any measure (Mann-Whitney U).

†Long-term retrieval is defined as the recall of a word (list of 12) that is in long-term storage. Words are in long-term storage if they have been recalled on two consecutive trials (for example, without reminding). Total long-term retrieval is the sum of LTR across 12 trials.

$\ddagger$ Thinking disturbance comprises 3 of the 18 scales on the BPRS (conceptual disorganization, hallucination, and unusual thought content), and has been shown to be a sensitive measure of emotional disturbance after closed head injury. ${ }^{14}$ 
enlargement and the presence of intellectual deficit, impairment from retrieval from long term memory, deficient information processing (PASAT) and thinking disturbance were pervasive in this series. In view of the differences in pathophysiology of injury, we computed the Spearman rank-order correlation coefficients between the neuropsychological test scores and the VBR for the early enlarging group $(n=16)$ and the other closed head injury patients $(n=23)$ separately. Although there was a trend for neuropsychological test performance (WAIS IQs, retrieval of a word list from long term memory storage, and information-processing rate) to be related to the magnitude of the VBR in patients other than the early enlargers, the correlation reached significance only for the Wechsler Verbal $(r=-0.49$, $\mathrm{p}<0.02)$ and Performance $(\mathrm{r}=-0.42, \mathrm{p}<0.04)$ IQ scores. There was no significant correlation between neuropsychological performance and the VBR in the early enlargement group nor did the highest correlation $(r=0.27)$ approach significance.

\section{Discussion}

Ventricular enlargement is a common sequel of severe closed head injury ${ }^{4}$ is despite the relatively infrequent finding of overt communicating hydrocephalus requiring shunt diversion of cerebrospinal fluid. Although Levin and colleagues ${ }^{4}$ reported a positive relationship between the degree of ventricular enlargement and the severity of diffuse injury (indexed by duration of coma), there were impressive deviations (for example, marked ventricular enlargement after a brief period of coma or no loss of consciousness) from this pattern. In the present study, CT evidence of subarachnoid/intraventricular haemorrhage or meningitis frequently complicated injuries which produced rapid but not delayed ventricular enlargement. Our findings do not exclude the presence of small amounts of blood in the cerebrospinal fluid (CSF) pathways which were undetected by CT in cases of delayed ventricular enlargement. It should also be noted that the degree of ventricular enlargement in our series was related positively to the clinical rank ordering of sulcal prominence, suggesting a generalised atrophic process.

Consistent with the hypothesis that delayed ventricular enlargement arises from severe diffuse axonal injury, ${ }^{1-3}$ the VBR was related positively to the duration of coma in patients other than the early enlargers. We recognise, however, that hypoxicischaemic injury and other insults also contributed to the severity of diffuse brain damage in these patients. ${ }^{3}$ Furthermore, early brain swelling/oedema could have delayed the appearance of ventricular enlargement in some cases. Although the neurologic course of only a single patient with early ventricular enlargement required placement of a shunt, there was a preponderance of subarachnoid and intraventricular haemorrhage which could have impeded CSF resorption in other cases in this group. Whether insertion of a shunt would facilitate recovery in patients with early ventricular enlargement but no other clinical symptoms or findings of progressive hydrocephalus awaits further study.

Our findings show that the degree of ventricular enlargement is related to both the duration of coma and to residual intellectual functioning except in the cases who developed ventriculomegaly within one month of injury. Hydrocephalus, hypoxic-ischaemic insult and diffuse axonal injury may combine in varying proportions to increase ventricular size during the first month after head injury. We suggest that the presence of ventriculomegaly has different prognostic implications for cognitive function if it occurs shortly following an injury as opposed to after a delay. The VBR is a useful prognostic index of recovery provided the time course of enlargement is considered.

This study was supported by grant NS 07377-11 (Center for the Study of Nervous System Injury), NS 9-2314, Comprehensive Central Nervous System Trauma Center Contract, and by grant $80-233$ from the Moody Foundation. We thank Pat Smith and Lori Bertolino for assistance in the data analysis and ,Sarah De Los Santos for typing the manuscript.

Portions of this paper were presented at the International Neuropsychological Society Meeting in Pittsburgh on February 5, 1982.

\section{References}

${ }^{1}$ Strich SJ. Diffuse degeneration of the cerebral white matter in severe dementia following head injury. $J$ Neurol Neurosurg Psychiatry 1956;19:163-85.

${ }^{2}$ Strich SJ. The pathology of brain damage due to blunt head injuries, In: Walker AE, Caveness WF, Critchley M. eds. The Late Effects of Head Injury, Springfield: Charles C. Thomas 1969. 501-26.

${ }^{3}$ Adams JH, Mitchell DE, Graham DI, Doyle D. Diffuse brain damage of immediate impact type. Brain 1977;100:489-502.

${ }^{4}$ Levin HS, Meyers CA, Grossman RG, Sarwar M. Ventricular enlargement following closed head injury. Arch Neurol 1981;38:623-9.

${ }^{5}$ Teasdale G, Jennett B. Assessment of coma and impaired consciousness: a practical scale. Lancet 1974;2:81-4.

${ }^{6}$ Plum F, Posner JB. The Diagnosis of Stupor and Coma. Philadelphia: F.A. Davis Co., 1980.

${ }^{7}$ Synek V, Reuben JR. The ventricular-brain ratio using planimetric measurement of EMI scans. Br J Radiol 1976;49:233-7.

${ }^{8}$ De Leon MJ, Ferris SH, George AE, Reisberg B, 
Kricheff II, Gershon S. Computed tomography evaluations of brain-behavior relationships in senile dementia of the Alzheimer's type. Neurobiology of Aging 1980;1:69-79.

${ }^{9}$ Buschke H, Fuld PA. Evaluating storage, retention, and retrieval in disordered memory and learning. Neurology (Minneap) 1974;24:1019-25.

${ }^{10}$ Gronwall D, Wrightson P. Recovery after minor head injury. Lancet 1974;2:1452.

${ }^{11}$ Overall JE, Gorham DR. The brief psychiatric rating scale. Psychol Rep 1962;10:799-812.
${ }_{12}$ Levin HS, Benton AL, Grossman RG. Neurobehavioral Consequences of Closed Head Injury. New York: Oxford University Press, 1982.

${ }^{13}$ Levin HS, Grossman RG, Rose JE, Teasdale G. Longterm neuropsychological outcome of closed head injury. J Neurosurg 1979;50:412-22.

${ }^{14}$ Levin HS, Grossman RG. Behavioral sequelae of closed head injury. Arch Neurol 1978;35:720-7.

${ }^{15}$ Kishore PR, Lipper MH, Miller JD, et al. Post-traumatic hydrocephalus in patients with severe head injury. Neuroradiology 1978;16:261-5. 